\title{
Hypothesis
}

\section{A Network Based Theory of Health Systems and Cycles of Well-being}

\author{
Michael Grant Rhodes* \\ Orrery Consulting, Prins Hendrikkade 160, Amsterdam, The Netherlands
}

\section{AR T I C L E IN F O}

\section{Article History:}

Received: 6 June 2013

Accepted: 14 June 2013

ePublished: 14 June 2013

\section{Keywords:}

Health Systems

Network Theory

Social Insurance

Public Health

Governance

\begin{abstract}
A B S T R A C T
There are two dominant approaches to describe and understand the anatomy of complete health and well-being systems internationally. Yet, neither approach has been able to either predict or explain occasional but dramatic crises in health and well-being systems around the world and in developed emerging market or developing country contexts. As the impacts of such events can be measured not simply in terms of their social and economic consequences but also public health crises, there is a clear need to look for and formulate an alternative approach. This paper examines multi-disciplinary theoretical evidence to suggest that health systems exhibit natural and observable systemic and long cycle characteristics that can be modelled. A health and well-being system model of two slowly evolving anthropological network sub-systems is defined. The first network sub-system consists of organised professional networks of exclusive suppliers of health and well-being services. The second network sub-system consists of communities organising themselves to resource those exclusive services. Together these two network sub-systems interact to form the specific (sovereign) health and well-being systems we know today. But the core of a truly 'complex adaptive system' can also be identified and a simplified two sub-system model of recurring Lotka-Volterra predator-prey cycles is specified. The implications of such an adaptive and evolving model of system anatomy for effective public health, social security insurance and well-being systems governance could be considerable.
\end{abstract}

\section{Background}

In all languages, and societies, few areas of public policy and dialogue have the ability to raise passions like health and well-being. New academic journals are then an essential part of not only stimulating but also informing such discussion. Yet seldom do we stop to consider the basic anatomy of health systems as a whole; interventions in which become so hotly debated.

Currently, there are two dominant approaches to describe and understand complete health and well-being systems internationally. In many ways, they represent the competing perspectives of two mutually dependent networks of human cooperative action in the pursuit of health and well-being. Yet neither approach has been able to either predict or explain occasional but dramatic crises in health and wellbeing systems around the world and in developed emerging market and developing country contexts. As the impacts of such events can be measured not simply in terms of economic and social consequences but also public health crises, there is a clear need to look for and formulate a third and alternative approach (1). System level crises also offer rare opportunities for autopsy. Against this background, this paper examines whether it might be possible to examine health systems in terms of those underlying networks and their interactions and critically therefore, as naturally occurring and observable complex adaptive systems. This would offer considerable opportunities to strengthen both health systems and their governance.

The paper starts with a brief introduction to a conceptual framework and some essential concepts in the methods used in the theoretical research. This is followed by the results which are presented in terms of supporting evidence and analysis that might be used to measure the growth of networks at the heart of health systems, and how they might evolve. Discussion focuses on future empirical opportunities, and the possibility of a more fundamental network based theory of human health and well-being systems.

\section{Conceptual framework and methodological approach}

The first approach to 'health systems', and that propounded by the WHO, is based around the basic bilateral relationship between 'providers' of care and well-being goods and services on the one hand, and 'patients' or 'clients'(recipients of services) on the other (Figure 1a) (2). The approach is uni-directional built on six functional building blocks with a focus on service delivery. The approach does not therefore

*Corresponding author: Michael Grant Rhodes; Email: orreryconsulting@gmail.com 
fully account for the duality to the participation of both basic parties in 'the system' framework. A second approach, which can be attributed to the OECD National Health Accounting framework, closes this circle by recognising 'patients' as sub-populations of wider groups and, at the highest current level of aggregation, national populations (Figure 1b). The approach illustrates feedback loops and mechanisms of mutual (inter-) dependence between primary actors and groups by including a set of third party 'financing agents/ payers' to quantify particularly financial and counterpart information transactions (3). A recent editorial in the Indian Journal of Public Health suggests, however, that a third approach might exist and that 'health and well-being systems' might also be viewed and analysed in terms of (anthropological or social) network theory and system science (4).

If viewed as (social) human networks, existing approaches to health and well-being 'health systems' can therefore be seen as consisting of two distinct areas of social interaction and cooperation. First, cooperation exists between medical and health professionals (5). Secondly, cooperation exists between communities of individuals seeking to pool resources to 'protect' themselves against the risk of expenses for those professional medical and health services through insurance, or economically equivalently in the case of social insurance systems; 'access' the same using public (compulsory) and collective means (6). In both cases cooperative behaviour is operationalised by creating networks.

Yet, while these two networks can be identified and studied independently, they also define each other. In the most simplified case, they can be modelled as two sub-systems at the heart of an 'adaptive system' of human wellbeing. Adaption takes place not in the fundamental relationship; but in the understanding and acceptance by both networks of what constitutes health and well-being and useful action towards that end. With advances in statistical text analysis, the discourses that manifest and articulate that 'understanding' can increasingly be measured.

The identification and measurement of human and social networks is a new and rapidly growing field of research (710). To date such analysis has not been applied to health systems. The identification and measurement of dynamic human networks requires the use of mixed qualitative and quantitative methods. Key components of analysis used in the identification and measurement of social and economic networks are:

- 'Nodes' ('players', 'individuals', 'agents') are the points that a network connects;

- 'Ties' ('links', 'paths', 'cycles') are the vectors that connect the 'nodes';

- 'Networks' ('graphs') are the 'micro-', 'meso-' and finally 'macro-' aggregations of nodes and subsequently (sub-) networks.

Nodes may therefore be individuals or groups in larger meta-networks; as cells are to trees and trees are to forests. 'Ties' may be 'directed' (broadly speaking 'one-way') or 'undirected' ('two-way') and 'strong' or 'weak' (for example, in terms of tangible bond such as a blood bonds, or in terms of intangible or abstract bonds such as association membership or even religious group identification). The long periods of induction and the high barriers to entry to medical and health professional groups, for example, means that even seemingly 'weak ties' between nodes of medical professional networks and members can become relatively 'strong' as a result of shared 'trust' and/or 'beliefs' amongst a group which enjoys significant 'social capital' (11). In medical and health professional groups these ties are also continually re-enforced through behaviour obligations on members to maintain licencing and membership (12).

The growth and decline of networks can then also be described mathematically. Where two networks can be described in terms of mutual dependence, it is therefore also possible to identify a complex adaptive system. If such a complex adaptive system can be identified it would offer a rich and deep vein for future research.

Below, qualitative evidence from documentary research across a number of currently distinct areas in social (particularly economics, sociology, and social anthropology), medical (including social psychology and psychiatry) and, natural, sciences is used to identify and specify two separate human networks in health systems and how they interact. Each section ends with a brief mathematical formalization of discussion.

\section{The WHO Health System Framework}

System Building Blocks

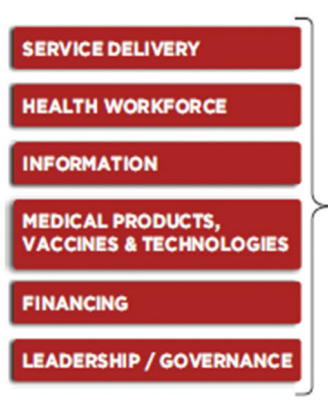

Overall Goals / Outcomes

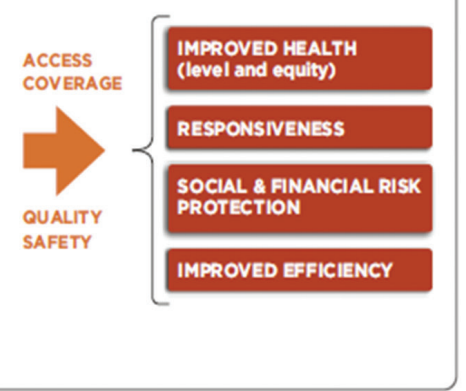

The OECD Framework for Accounting Health Systems

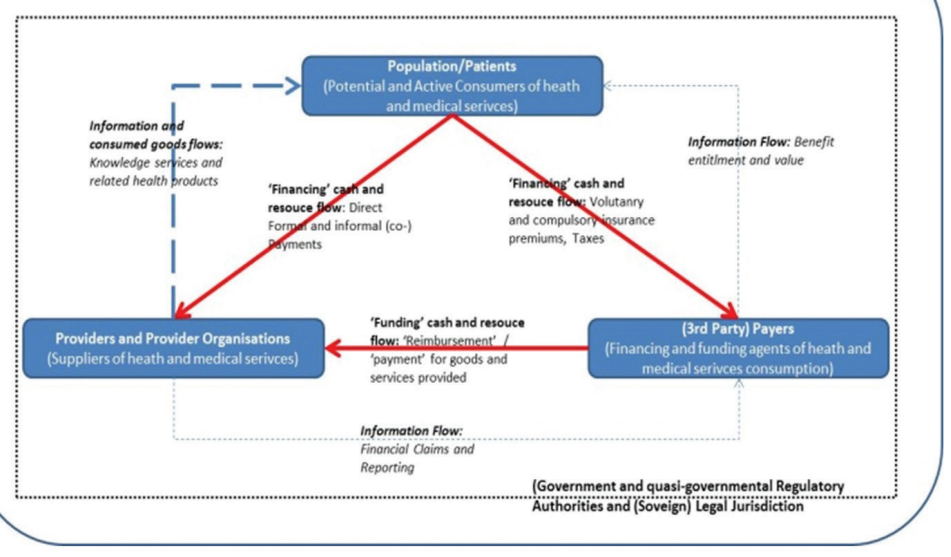

Figure 1. a) WHO (2) and b) OECD (3, revised) frameworks for describing health systems 


\section{Evidence and analysis}

From the perspective of medical and health professionals 'health systems' are not simply health care organisational arrangements for providing medical and public health related services. 'Health (and well-being) systems' describe all formal and informal efforts, organizations and associations with the purpose of promoting and maintaining human health and well-being (13). That is, networks with links and nodes both between professionals, and between generations of professionals. That purpose is then identified by the ability and focus of the (professional) groups and networks concerned to: collect, disseminate, communicate and hence control, information and 'evidence'- amongst therefore a recognised and exclusive (closed access) professional group-relating to medicine and individual and public health (social medicine). A group historically referred to as a 'guild'. By their nature, professional networks or guilds then also become recognizable, distinct and observable sociological network phenomena (5). Medical and professional literature then also becomes a cross sectional and time series trail of recorded transmissions amongst members.

The history of medicine stretches back to the first civilisations, but the systematic registration and crossreferencing of health and medical knowledge only occurred in the early to mid-nineteenth century (14). Two of the first and most important instruments for this continue to this day: The Lancet (1823) and the BMJ (1840). In a little more than 100 years, medicine and it professional practitioners and bodies (which in British, then imperial and global territories had only elevated themselves from sawdust of the barbershop in 1745) become the crown jewel and arguably defining totem of modern welfare states (15). Medical journals continue to play a fundamental part in this process.

The original medical journals had two purposes. First, the goal was to create platforms to share knowledge that genuinely improved human health and wellbeing. The problem was simple. By the mid-nineteenth century, medical and health related professionals (and indeed the population at large) were as plagued by charlatans, as enlightened by the first pioneers of modern science. There was no shared system of medicine. Medicine was not a science. Nor, due to the lack of knowledge, was there any 'system of health', public health, or more than even rudimentary sanitary control. Only in 1854, and after much resistance from by then already well-organised defenders of scientific orthodoxy, did John Snow publish his seminal study on the Broad Street water pump and London cholera epidemic of that year (16). When Thomas Wakley MP (member of parliament) founded The Lancet in 1823 the goal was very clear: "A lancet can be an arched window to let in the light or it can be a sharp surgical instrument to cut out the dross and I intend to use it in both senses". This remains the stated philosophy of the journal to this day.

Secondly, these information platforms had the overtly social or political aim to organise professional networks that, to that time, had remained largely artisanal. A craft passed down from master to student. Access to medical and health professions through such licencing remains similarly restrictive to this day. The editors of the first edition of the
Provincial Medical Society Journal (later the British Medical Journal or BMJ) were as clear in their goals as their London colleague Thomas Wakley had been 17 year before, namely: "(to promote) medical practitioners, as a class in the rank of society which, by their intellectual acquirements, by their general moral character, and by the importance of the duties entrusted to them, they are justly entitled to hold" (17).

Since the first editions of these seminal publications, each new generation of health/medical/scientist professionals has branched out into new fields and the number of official journals has expanded. Indeed by 1995, there were an estimated 20,000 medical and health scientific journals worldwide. So many in fact, that a World Association of Medical Editors convened in Bellagio Italy to discuss possibilities and approaches to coordinate efforts to maintain (minimum scientific) standards (18). The border between medical and health related sciences and commercial or social marketing and (political) activism was blurring (19).

This professional history is not only remarkable, particularly as key Medical Journal such as the Lancet and the BMJ continue to be amongst the most influential 'scientific' publications in the world to this day, but also because it raises an interesting possibility. Taking The Lancet and BMJ as the first successful attempts by organised groups of medical professionals in the modern era to both: systematise medical and health related (scientific) information and knowledge through publication, and; organise and bind a wider network of medical professionals through first peer review and second peer recognition in the use and control of that information; it is possible to sketch the outline of the recorded historical path from those first journals in 1823 and 1840 to present day.

Let us define cells of individuals around the formation of a new peer science/health journal as a micro-network or college. These colleges then form 'nodes' in a collegia mesonetwork. Each node can divide (reproduce) as the member (s) of any college stick or split to form a new college micronetwork and associated journal. The collegia meso-network grows. Finally, as collegia grow, a recognizable collegium (macro-network) emerges as associations associate. Critical to hypothesising such a growth path would be evidence of some cell division and reproductive connection between the first college micro-networks. The Lancet and BMJ provide just such a link. Not least, Peter Hennis Green (18031870) an Irish physician, lecturer at the Huntarian School of Medicine in London, and a first editor of the BMJ (then PMSJ) also wrote many columns for The Lancet between 1820 s to the 1840 s under the pseudonym, Erinensis.

Assuming no mutations and a continued binomial division (transformation matrix) every 17 years (translation matrix), we could expect The Lancet (1823) and the BMJ (1840) to have resulted in just over 1000 journals and medical/ scientific (micro-) network off-spring by approximately 1995. This is somewhat less than the 20,000 observed, but clearly any number of mutations might occur. Even the simplest iterative fractional system therefore provides remarkable results as even the smallest mutations $(<1+\mathrm{x}$, where $0<\mathrm{x}<1$ ) in off-spring at each generation, and the observed result would be quickly generated. Applying 'fractal' rather than 'fractional' iterations might even create 
the possibility of compounding growth into distinct network topologies recognizable in 'integrated medical and (public) health systems' today.

Finally, it is now also possible to suggest a standard logistical model for the growth of 'health systems' when defined as organised medical and health related professional networks without constraints. The solution to which is an exponential function (Equation 1):

Equation 1: $\frac{D N}{D t}=r N$

Where:

$\mathrm{N}=$ The population of (medical and health professional sub-specialisation) nodes (in the health system network).

$r=$ A natural growth rate of the network nodes of health professionals (a proportionality constant).

The volume and diversity of observed official medical journal titles today may therefore belie a more simple and fundamental feature of 'health systems' as professional group networks. However, diverse professional groups in health may appear, they are 'viral collaborative networks' with a shared DNA. Yet while potential to expand knowledge to improve human health and well-being, and therefore also the networks of (legally privileged) individuals to pursue, interpret and implement this knowledge may tend to the infinite; the real growth of these professional network populations clearly is not. The (albeit very slowly operating) viral collaborative growth of professional networked (sub) populations in a society and sovereign legal jurisdiction cannot happen in isolation from the rest of that society. A more realistic model therefore says that as a (sub) population grows in a closed system, it increasingly competes with itself and its growth rate decreases linearly. The differential equation to describe this feature of (subsystem) population growth in closed systems is sometimes called the logistical equation:

Equation 2: $\frac{D N}{D t}=r\left(1-\frac{N}{\mu}\right) N$

Where, in extension equation 1 :

$\mu=\mathrm{a}$ containing factor (or, in the terminology of biological and ecological 'predator-prey' type models used later in this paper, the 'carrying capacity' or 'food supply' in a system).

Viewing medical, health and well-being systems first in terms of the underlying sociological and anthropological subsystems, the question then inevitably arises; If medical and health professional network sub-systems end up competing with themselves, who do they start out competing with and which other human social and anthropological subsystems form the 'food supply' or constraining factor on their growth? To answer this question is again necessary to consider qualitative evidence and the historical record.

On March 14, 1942, the first patient was treated with a Merck Company produced anti-biotic for streptococcal septicemia (20). Half the total supply available was used on that patient. By June 1945, 646 billion units were being produced by the War Production Board and distributed. In a different era, Edward Jenner had experimented with a smallpox vaccine as early as 1796 but it was only in 1979 that the WHO declared smallpox eradicated. Both reflect remarkable scientific discoveries. Yet while the Second World War coincided with a number of important scientific and technological innovations in medicine and science, the command and control systems and collective imperatives of war created the conditions for a logistical, as much as scientific and technological, marvel. The traditional constraint to expanding access to the discoveries of science and the services of medical professionals to implement them was temporarily lifted, or at least minimised.

Prior to 1883, if a European citizen had been sick, he or she had only three basic options: First, pay for treatment themselves or through family, 'clan' or 'tribal' networks; Secondly, seek (private) charitable assistance provided by one of many social movement networks relating typically to either religious organizations, and/or; thirdly, postpone or forego available treatments. Public spending (compulsory finance revenues) on health care was limited to restricted groups of public, and particularly military, employees. Private commercial voluntary insurance against (exclusively) health care expenses barely existed although private non-profits, cooperatives and friendly societies had started to provide some support in this area (21).

However, in 1883 in what would prove to be an ultimately unsuccessful attempt to stem the rise of then nascent German Socialist Party (SPD), the Bismarck administration included protection against medical expenses in a radical program of social insurance and welfare reforms. For the first time in history, medical professionals did not have to rely purely on income from private patients, family and clan social structures, private membership societies, and/or charitable largesse to extend their services to a wider public. Health care became a universal entitlement but also, and crucially to the argument here, the financial responsibility of clearly defined social macro-network - all members of a sovereign (Westphalian) state. The precedent for the modern welfare state had been established.

The medical care, the treatment of sickness and ill-health, actually covered under Bismarck's reforms was itself initially extremely limited - primarily because medicine itself was very primitive. But the perceived value of available medical technologies and services was sufficiently high to warrant such mainstream large scale political competition. That is, competition to represent the interests of an anthropological meta-group clearly identifying themselves on the basis of: geographical security and legal and fiscal sovereignty. Language (cultural identity) and tradition therefore also played an important role. 'Social insurance' (Sozialversicherung or volksversicherung) became an early and successful attempt to deliberately 'frame' (that is, apply what are now the insights of social-psychology and psychiatry) to what was effectively 'income tax' (22). ${ }^{1}$

It was only after 1945 , that the bulk of remaining European states and their colonial possessions, but also China and therefore the overwhelming bulk of world populations, would arrive at the similar destination, albeit via a different

1. The actual translation of discourse therefore more accurately: 'collective-', 'national-' or 'citizens-' insurance. 
route.

Distinct from medical services (the treatment of ill health and unwell-being) rapid urbanisation and industrialisation in the nineteen century also saw the rise of public 'hygiene' and 'sanitation' administrations to promote and protect health. Through colonial administrations these systems spread their arms world-wide (23). But the modern cities of the industrial revolution were not healthy places to live (24). While conditions for the poor were quite literally Dickensian, infectious diseases and ill-health spared neither rich nor poor. Action to promote health and well-being -as opposed to simply treat ill-health through medicine- was demanded and ultimately achieved at the societal or 'social' level. Public Health, Sanitation and Hygiene administrations grew out of significant social movements of the day, for example: social housing; industrial safety; children's education (anti-childlabour); water and sanitation; abstinence and temperance (25).

In the pre-information and mass-media (colonial and imperial) age, the hierarchical administration systems developed of; 'a priest in every parish', creating a cheap and efficient network of communication channels for public health information and programmatic coordination in which only a few degrees of separation connected root nodes of hierarchical public health and hygiene administration sand almost the entire world population. The channels just needed to be deepened and widened over time.

Only in the 1920s and 1930's', in the Soviet Union and its imperial territories were (individual) medical and health services (i.e. the treatment of sickness and ill-health) and (collective) public health, sanitation and hygiene administrations (i.e. the promotion and protection of health) "integrated" for the first time. The 'Integrated Public Health System' created, and now synonymous with Beveridge and the United Kingdom's National Health Service (NHS), can in fact be traced to the eminent Russian Professor of Social Hygiene and first Soviet Minister for Health; Nicolai Semashko and the so-called 'Semashko System' (26). At the same time, the Semashko system reflected an alternative Soviet Socialist vision for organising social security and well-being insurance.

As under Bismarck's reforms fifty years earlier, all Russians were brought: from many small insurance arrangements, or indeed none; to one single national 'risk pool' or social security network for health and well-being purposes. All previously prevailing arrangements and networks for social security were consolidated. The principle difference between the two approaches being: under the Bismarck system a clear institutional distinction was made between 'financing/purchaser' agent(s) on the one hand, and 'provider' (medical and health service supplier) agent(s) on the other. This is a feature of the Bismarckian design of a 'health system' that gave it some potential for 'system resilience' and to which we will return. In the Semashko and Beveridge (NHS) systems on the other hand no such distinction was made in favour of a single super integrated hyper-agent, combining not only social (public health and hygiene) and individual (medical service) health functions, but also funding and 'purchasing' functions. This is a feature of the Beveridge design of a 'health system' that gave it potential for 'system power'; and to which we will return.
Individual citizens or networks and organisation of citizens may have (had) some political representation toward such hyper-agents; but direct authority or the ability to switch agents was removed to be exercised by central public administrations and authorities.

Each of these sources and evolutions of social security networks are summarised in what is sometimes referred to as the points - and networks - of a welfare and social security 'pentagon' (Figure 2) (27).

By 1948, all then developed countries with the exception of the United States had joined the revolution that had been started by Bismarck. ${ }^{2}$ A commitment also enshrined in the Universal Declaration of Human Rights after the Second World War. Either through direct taxation revenues or social insurance contributions (i.e. compulsory hypothecated income taxes), all had introduced some form of national universal payment (and access) for either a distinct set of 'medical services' and 'public health services' or some form of 'integrated health system' of the two. Significantly, in both systems, long established medical and health networks were also brought into the heart of public administrations. A profession that had been confined by the financial limitations of serving selective groups could now serve entire sovereign populations without constraints. The only remain factor limiting growth was what might be described as the relative nutritional value of that 'food supply'. Seminal evidence from the health economic literature would strongly support such a conclusion (28).

Again it is now possible to describe this historical process of the gradual fusion of insurance micro-networks into modern insurance meso-networks and finally to macronetworks (be that from: informal family arrangements to and through formal clan, regional, trade or professional group social security pools) into single national 'social insurance' (meso-network linked for example through risk adjustment ) or simply 'taxed based' or 'single payer' health care and public health systems(be they integrated or not) in terms of a second logistical equation; and a second distinct network sub-system. It is also worth noting that such a bottom-up human network formation process for the development of (medical insurance) social security now forms the basis of such instruments as community based insurance and micro-insurance in low income countries (29). We can also say that, independent of cultural or historical settings, political discourses, linguistics, or historical progress, the ultimate destination to date has been that all members of a Westphalian state are grouped together in one sovereign state 'risk pool' or macro-network.

The history of the financing of health care and other social security arrangements is the history therefore of ever expanding aggregations of groups and networks of people pooling their resources to do so. It is a sociological and anthropological as much as an economic and financial history. In other words, in terms of Equation 2, the constraining factor $(\mu)$ on the growth of medical and health related networks, the number of possible social security networks population members whose 'food supply' value can be accessed, could also said to be minimised. Only

2. The United States had to wait until 1965 and the Social Security Laws of Lindon Johnston and the introduction of Medicare (for the elderly) and Medicaid (for unemployed). It might also be argued that the United States had to wait until the Affordable Care Act of the Obama administration (2012). 


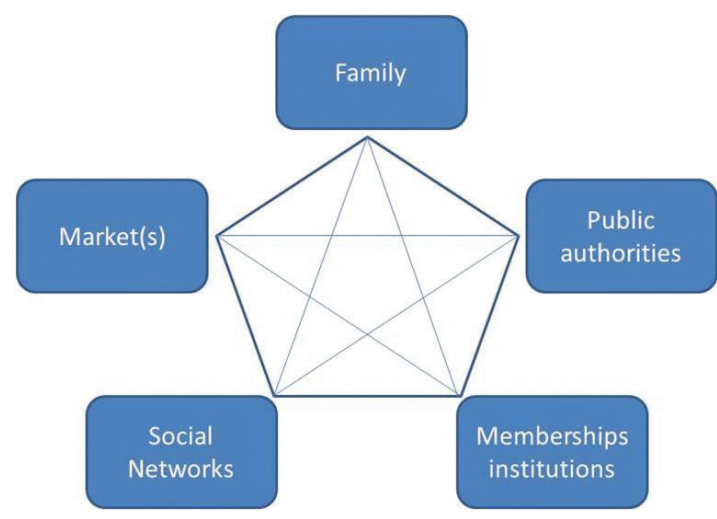

Figure 2. Network connections across the welfare pentagon (27)

one further network aggregation is possible; that of the fusion of the social security arrangements of nation states. Within sovereign legal jurisdictions however, the networks of medical and health professional populations become generalised 'alpha predators' able to range across all 'social security' herds and sub-populations; and these subpopulation therefore become one with respect to networks of medical and health professionals.

Equation 2 can now be re-specified. In the most extreme but simple case - where 'universal coverage' (either through general taxation revenues or 'social insurance' (with or without 'risk adjustment' constructions) is achieved - all non- medical and health related persons and networks are brought into a single and clearly identifiable 'risk pool' group and network - the citizenry of a sovereign jurisdiction. The constraining factor on the growth of the population of medical and health professionals then becomes precisely that for which they were called into existence; the growth of the ('health and well-being' of) human populations who, in turn, aggregate in expanding networks for purposes of medical and health social security to the same end.

The equation for the growth of the exclusive professional health and medical services population, under the assumption that it is entirely controlled by the 'health and well-being' of the populations served and who pool resources to be served (the networked social security populations to be served) can now be described as:

Equation 3: $\frac{D P 1}{D t}=-\left(1-\frac{P 2}{\mu 2}\right) P 1$

\section{Where:}

P1 = The growth of population of medical and health networks

P2 = The growth of population (density) of social security networks

$\mu 1=$ The constraining variable or 'carrying capacity' of population P1

$\mu 2=$ The constraining variable or 'carrying capacity' of population $\mathrm{P} 2$

The extra minus sign in equation 3 distinguished the 'predators' form the 'prey'. Note if Y2 becomes zero, $\mathrm{Y} 1=-\mathrm{Y} 1$

Equally, we can say that, as the purpose of the growth of the populations of networked medical and health professionals
(Equation 3) is assumed to be the sole determinant (exclusive agent) of the 'health and well-being' of the networked population for mutual social security, a second matching differential equation can also be specified for the growth of the population of grouping into 'social security herds' (Equation 4).

Equation 4: $\frac{D P 2}{D t}=\left(1-\frac{P 1}{\mu 1}\right) P 2$

Not only can we now explain the interdependent growth of groups of medical and health professional and the growth of mutually insured networked populations for health and well-being; Equation 3 and 4 share an additional, and remarkable, property. They form the basis of a Lotka-Volterra type model of so-called 'predator-prey' cycles $(30,31)$. Equation 4 may determine the growth and constraints on growth of Equation 3, but the opposite is also true. Predator populations expand with prey populations but also decline as prey numbers dwindle. Where predators reproduce more slowly than a prey population, a time lag can occur and the possibility of both dramatic increases (in benign conditions for prey) and subsequently equally dramatic collapses in both populations. Lotka-Volterra models are therefore simplified examples of complex adaptive systems.

More fundamentally, Lotka-Volterra models are unusual amongst non-linear systems in that they provide only periodic solutions. That is, they cannot provide a solution in terms of any elementary, for example trigonometric, function. It is necessary to compute separate numerical solutions for each function giving a graph with two interwoven cyclical oscillating trends. Network populations will aggregate and then disaggregate in repeating cycles. This would imply that networks of medical health and well-being professionals, but also social security networks combine first as micro-, then meso- and finally as macro-networks, but then also decompose. In this case, the cycles implied are very long. Any macro-network, at whatever scale, is therefore not an inevitable or permanent end point but an observation at one historical moment. The implications of such a result for how we could and should think about health systems would be significant.

\section{Discussion}

The true test of a model is whether it can be used to offer insights to explain observed phenomenon. Within the inevitable constraints of residual risk and uncertainty, models might even be used in an attempt to anticipate events yet to take place, or the likely consequences of possible choices or changes in factors thought to influence those events at given moments in time. There are many potential implications and possibilities if both the model and methods of this paper can be expanded upon, but perhaps the most appropriate starting points for discussion and further debate would be: First, 'Does the new model respond to any limitations in existing models and frameworks used to describe and understand health and well-being systems?', and: Secondly, 'If a new theoretical model offers new insights, what might be the practical applications?'

To understand the limitations of existing health (care) systems models and frameworks one has only to look 
back to the momentous events of 1989 in Central and Eastern Europe. Viewed at the start of 1989, the collapse of the (until that date much vaunted) health and well-being systems of the former Soviet Union or Yugoslavia had been inconceivable. Few if any predicted what would happen. Yet only two years later, the (single payer) 'integrated health systems' throughout the region had all but collapsed. Key population health and well-being indicators plummeted (1). The inability of existing analytical frameworks to anticipate or even explain the events the took place at that time, and may now be unfolding in other regions of Europe and the world, suggest that not only are current models unsatisfactory; but that there is also an urgent need to find an alternative.

In fact, current models would seem to do little more than suggest or reflect politico-legal models and frameworks, albeit described (or 'framed') in the different legal traditions, languages and discourses of the many societies and cultures around the world. There is no recognizably 'scientific' system, to health and well-being 'systems'. The proposition of this paper is that system science, the study of networks, does offer such a system. Not only that, the model proposed suggests that such a system is composed of two primary sub-system networks, caught in a continuous, conflicting, and yet harmonious struggle for survival. This would also have important implications for policy options and choices within those networks.

Amongst the world's networks of medical and health professionals, their gradual integration in the continuous pursuit of the science of delivering better health and health services cannot be divorced from the necessary conditions of continuously integrating social security arrangements and networks. Nor indeed the professional interests that such a pursuit might also imply.

One option already proposed by a number of groups in public debates on extensions to the UN Millennium Development Goals (MDG) might therefore be to keep integrating health systems to the concluding point of creating one system of global health and social security (32). However, even imagining such an historically epic solution were possible, particularly with respect to social security networks, the network model of health and wellbeing systems proposed in this paper would suggest that, in the absence of the discovery of a new world, sooner or later a globally integrated health and well-being system would suffer a therefore equally global collapse. That is, sooner or later, and assuming that not all variables can be constant and endogenous there would be a global collapse of both medical professional and social security insurance network sub-systems.

The implications of such a singularity event would be dramatic. Hence, in the same way that the prevention of small forest fires only increased the likelihood of less frequently but more dramatic and damaging large forest fires through fire exclusion; the alternative might be to accept frequent small loses as the price of avoiding occasional catastrophic loses. The true alternative to integrated networks and systems is therefore be not 'fragmented', but decentralised and distributed, networks and systems.

With respect to creating alternative network structures of health information and knowledge one such proposal is the creation of Open Collaboration Platform(s) or 'Public Health Meshes' of individual related health data (4). By connecting and aggregating (potentially even in real time and privacy secured) even very limited numbers of data fields in (electronic) patient records and other health and behaviour related data sources; a medical technology appraisal, public health and epidemiological intelligence and learning system could be created, potentially from extremely small seed projects, but that would have the potential to far exceed current epidemiological surveillance systems based largely on existing (hierarchical) integrated medical and health professional networks and stemming for a time when such data were barely robustly recorded on paper. Such a system of (social medicine) health intelligence could even incorporate non- and even anti- medical, health, co-production and alternative professional groups, approaches, processes and information (33).

In terms of the system model suggested, such an approach would therefore also have the advantage of allowing high levels of information and knowledge integration, without requiring high levels of integration of either: medical and health professional (and enterprises) networks, or; social security networks. Degrees of integration of both that would be progressively more difficult to achieve, and not without short-comings.

Finally, it is with respect to higher degrees of integration amongst (health) social security networks and risk pools that these short-comings will be most pronounced. It may be the case that highly diverse communities at sub-, national, and super-national levels can be persuaded into ever expanding singular risks pools but the model proposed here would suggest any such process would be incremental, starting from the bottom up, and slow. Furthermore, particularly at increasing scale, multi-level risk pool network structures such as multiple social insurers connected by (variable to full) risk adjustment or equalisation, as opposed to single payer structures, may offer both micro and macro network risk management advantages. This is a particularly important result with respect to operational considerations relating to the recent World Health Assembly resolution WHA58.33 (sustainable health financing, universal coverage and social insurance).

The progressive integration of the networks in the system approach described therefore holds not only the opportunities for rare but wonderful discoveries that deliver health impacts, but also rare and catastrophic risk events that will have the opposite effect. Balancing these opportunities and challenges is the real challenge ahead in health system governance, policy and management.

\section{Future research}

Extremely large scale, system level crises and subsequent developments in health systems in particularly Central and Eastern Europe over the last 25 years offer rare natural experiments to test the model presented in this paper (1). Other parts of the world have also experienced similar critical events. Subsequently, once the networks described have been identified, not only can factors affecting their growth or decline be considered, but it is also possible to consider issues of 'social contagion' or 'social influencing' within and/or across these networks (34). That is, through 
discourse analysis, to study the transmission of ideas or technical knowledge and (exclusive) group: language, behaviours or identifiers $(35,36)$. Thirdly, computer assisted statistical text analysis and meta-data are making particularly linguistic patterns increasingly observable at very large scale and these have also already been linked to other critical and large scale social and economic events such as stock market crashes (37). Each of these areas offers potential for future research.

\section{Conclusion}

This paper proposes that network and (adaptive) systems based approaches can be used to measure and analyse quantitatively, the qualitative wealth of political economic systems for human health and well-being. But such an approach is not without its draw-backs. First, such an approach would seem to suggest that in the governance of such systems we will be confronted with choosing between system power and system resilience. Secondly, if we were to choose resilience and the flexibility at micro-network levels to survive shocks and changes to ensure macronetwork security, the benefit would be the reduced risk of catastrophic events, but the price would be accepting more frequent micro-network failures. Similarly, if we were to choose to attempt to muster the power to attempt to prevent any adverse events for micro-networks or their constituent elements, the price would likely be rare but potentially catastrophic macro-network events.

There is therefore also a fundamental philosophical choice and value judgement at the heart of any decision between integrated or distributed network architectures. Decentralised and distributed network architectures and network topologies in system governance would imply a distinctly utilitarian (vertical equity) moral framework, as opposed to the more 'social justice' or 'rights based' (horizontal equity) moral and legal frameworks of more integrated and hierarchical network architectures in the governance of health and well-being systems (38). Both have their strengths and both weaknesses. Hence any choice may not come down to an optimal decision, but a trade-off and acquiescence with a lesser of two evils.

\section{Acknowledgements}

I would like to thank Prof. M. de Vries (Social Psychiatry, Maastricht University) whose belief in this paper made it possible.

\section{Ethical issues}

Not applicable.

\section{Competing interests}

None.

Author's contribution

MGR is the single author of the manuscript.

\section{References}

1. McKee M. Understanding population health: lessons from the former Soviet Union. Clin Med 2005; 5: 374-8.

2. WHO. Everybody's business - strengthening health systems to improve health outcomes. WHO's framework for action. Geneva: World Health Organization; 2007.
3. Hurst J. The Reform of health care: a comparative analysis of seven OECD countries. Economic and Social Development Paper. Paris OECD; 1992.

4. Rhodes G. The medical mandala: The public health benefits of entrepreneurship tools and skills among medical students in India. Indian J Public Health 2012; 56: 105-9.

5. Light D. The Sociological character of health care markets. In: Albrecht G, Fitzpatrick R Scrimshaw S. eds. The Handbook of Social Studies in Health and Medicine. Sage $2^{\text {nd }}$ ed. London: Sage; 2003.

6. Schieber G, Maeda A. A Curmudgeon's Guide to Financing Health in Developing Countries. In: Schieber G. ed. Innovations in Health Care Financing. Washington DC: World Bank; 1997.

7. Jackson M. Social and economic networks. Princeton University Press; 2008. p.20-51.

8. Christakis N, Fowler J. The Collective Dynamics of Smoking in a Large Social Network. N Engl J Med 2008; 358: 2249-58.

9. Demange G, Wooders M. (ed.s). Group formation in economics; Networks, clubs and coalitions. Cambridge: Cambridge University Press; 2005.

10. Rothenberg R. Social network dynamics and HIV transmission. AIDS 1998: 12; 1529-36.

11. Liou Y, Daly A. Closer to learning social networks trust and professional communities. Journal of School Leadership. [In press]

12. Jones W, Avant R, Davis N. Task Force Report 3. Report of the Task Force on Continuous Personal, Professional, and Practice Development in Family Medicine. Ann Fam Med 2004; 2: s65-74.

13. WHO. The world health report 2000 - Health systems: improving performance. Geneva: WHO; 2000.

14. Broman T. The Medical Sciences. In: Roy Porter (ed). The Cambridge History of Science: Volume 4: 18th-century Science 2003; p.465-8.

15. Bruce M. The Coming of the Welfare State. $4^{\text {th }}$ ed. London: Batsford; 1972.

16. Vinten-Johansen P, Brody H, Paneth N, Rachman S, Russell Rip M. Cholera, Chloroform, and the Science of Medicine: a Life of John Snow. Oxford: Oxford University Press: 2003.

17. PMSJ. Introductory Address. Prov Med Surg J 1840: 1; 1.

18. BMJ. World Association of Medical Editors (WAME) launched. BMJ 1995; 310: 761-2.

19. Williams A. Science or marketing at WHO? A commentary on 'World Health 2000. Health Econ 2001:10; 93-100.

20. Grossman C. The First Use of Penicillin in the United States. Ann Intern Med 2008; 149: 135-6.

21. Barr N. The economics of the welfare state. $2^{\text {nd }}$ ed. Oxford University Press; 1993.

22. Gross K. Framing Persuasive Appeals: Episodic and Thematic Framing, Emotional Response, and Policy Opinion. Polit Psychol 2008; 29: 169-92.

23. Lewis J. The British Empire and world history: welfare imperialism and 'soft power' in the rise and fall of British rule. In: Midgeley, James and Piachaud, David, eds. Colonialism and welfare, social policy and the British imperial legacy. Cheltnam: Edward Elgar Publishing; 2011.

24. Leon D. Cities, urbanization and health. Int J Epidemiol 2008; 37: 4-8.

25. Porter D. Health, Civilization, and the State: A History of Public Health from Ancient to Modern Times. New York: Routledge; 1999. p. 79-97.

26. Vienonen M, Wlodarczyk W. Health care reforms on the European scene: evolution, revolution or seesaw? World Health Stat Q 1993; 46: 166-9.

27. Neubourg C. de. The welfare pentagon and the social management of risks. In: Sigg R, Behrendt C. eds. Social security in the global village. New Brunswick: Transaction publishers; 2002. Vol. 8, p. 313-31.

28. Newhouse J, Phelps C. Price and Income elasticities for medical care services. Santa Monica: RAND (NBER); 1974.

29. Preker AS, Carrin G, Dror D, Jakab M, Hsiao W, Arhin-Tenkorang D. Effectiveness of community health financing in meeting the cost of illness. Bull World Health Organ 2002: 80; 143-50. 
30. Lotka AJ. Elements of physical biology. Baltimore: Williams \& Wilkins Co; 1925.

31. Volterra V. [Variations and fluctuations of the number of individuals in animal species living together]. Mem. R. Accad. Naz. dei Lincei 1928: 3; 3-51.

32. Ooms G, Hammonds R. Scaling Up Global Social Health Protection: Prerequisite Reforms to the International Monetary Fund. Int $J$ Health Serv 2009:39; 795-801.

33. Duhl L. The social entrepreneurship of change. Pace University Press $; 1990$.

34. Anagnostopoulos A, Kumar R, Mahdian M. Influence and Correlation in Social Networks. Proceedings of the 14th ACM SIGKDD International Conference on Knowledge Discovery and Data Mining (KDD), 2008. Available at: (http://videolectures.net/mlg08_mahdian_icsn/).

35. Gee J. An Introduction to Discourse Analysis: Theory and Method. London: Routledge; 2005.

36. Harris Z. A Theory of Language and Information: A mathematical approach. Oxford \& New York: Clarendon Press; 1991.

37. Gerow A, Keane MM. Mining the Web for the Voice of the Herd to Track Stock Market Bubbles. Proceedings of the 22nd International Joint Conference on Artificial Intelligence (IJCAI ‘11), Barcelona, Spain, 16-22 July, 2011.

38. Le Grand J .Equity as an economic objective. J Appl Philos 1984; 1: $39-51$. 